\title{
A CPW-FED ANTENNA RECTANGULAR SHAPED BOX WITH SEMICIRCLE SLOT FOR WLAN/WIMAX/UWB APPLICATIONS
}

\author{
Supriya Arora ${ }^{1}$, Davinder Parkash ${ }^{2}$ \\ ${ }^{1}$ M.Tech. Scholar, ${ }^{2}$ Assoc. Prof., ECE Department, HCTM Kaithal, Haryana
}

\begin{abstract}
An Ultra-wideband (UWB) microstrip antenna fed by a coplanar Waveguide (CPW) is proposed. The proposed antenna consists of a rectangular shape box embedded with semicircle slot in the patch. It occupies a total area of $39 \times 36.275 \mathrm{~mm}^{2}$. It provides a wide impedance bandwidth of $7.39 \mathrm{GHz}$ ranging from $2.66 \mathrm{GHz}$ to $10.05 \mathrm{GHz}$. The parametric studies are performed to understand the characteristics of proposed antenna. The details of proposed ultra-wideband are described. The various antenna parameters like $S$ parameters, current distribution and radiation pattern are studied. The proposed antenna is also suitable for WLAN/WiMAX/ UWB applications.
\end{abstract}

Keywords: Microstrip Antenna, WLAN, WI-MAX, UWB, CPW feed.

\section{INTRODUCTION}

Ultra-wideband (UWB) radio is an emerging and promising technology with uniquely attractive features inviting major advances in wireless communications, networking, radar, imaging, and positioning systems [1-2]. In the U.S., the Federal Communications Commission (FCC) allocated the frequency band 3.1-10.6 GHz for UWB applications in 2002. To satisfy these requirements, various wideband antennas have been studied. In either conventional communication systems or UWB communication systems, an antenna plays a very crucial role. Nevertheless, there are more challenges in designing UWB antennas than a narrow band one. Recently, there are various types of UWB antennas which have been designed to achieve the requirement for different applications [3-8]. Planar UWB antennas have been realized by using either microstrip line or $\mathrm{CPW}$ feeds. The $\mathrm{CPW}$ feeding has many attractive features, such as no soldering point, easy fabrication, and a simplified configuration with a single metallic layer.

The described antenna design satisfies UWB alongwith WLAN/WiMAX standards. This antenna cover the WLAN 5.2 GHz (5150-5350 MHz) and $5.8 \mathrm{GHz}(5725-5825 \mathrm{MHz})$ and WiMAX 3.5/5.5GHz (3400-3600/ 5250-5850 MHz) bands. The details of the proposed antenna design are presented and discussed in section 2. Simulated results and discussions are provided in section 3 , and conclusions are presented in section 4.

\section{ANTENNA GEOMETRY}

The geometry of the proposed monopole antenna is shown in Figure 1. The total size of the proposed antenna is $39 \mathrm{~mm} \mathrm{x}$ $36.275 \mathrm{~mm}$. As shown in the figure, the antenna consists of rectangular box shape embedded with semicircle shape slot in it. The antenna is fed by Coplanar Waveguide (CPW) feeding. The ground size of the proposed antenna is $13.6 \mathrm{~mm} \times 14.5$ $\mathrm{mm}$. The ground plane is symmetrical at the base line of the feeding strip line. To obtain the optimal parameters of the proposed antenna for WLAN/WiMAX/ UWB application, IE3D, 14.10 version of Zeland that can simulate a finite substrate and a finite ground structure, is used. Thus, the proposed antenna design can provide a wide bandwidth while retaining stable performance via the optimized geometrical parameters. The parameters of proposed antenna are shown in Table 1. The distance between patch and ground is $1.4 \mathrm{~mm}$ and between feed and ground is $0.5 \mathrm{~mm}$. The rectangular strip feed line has dimensions of $15 \mathrm{~mm} \times 4.5 \mathrm{~mm}$.

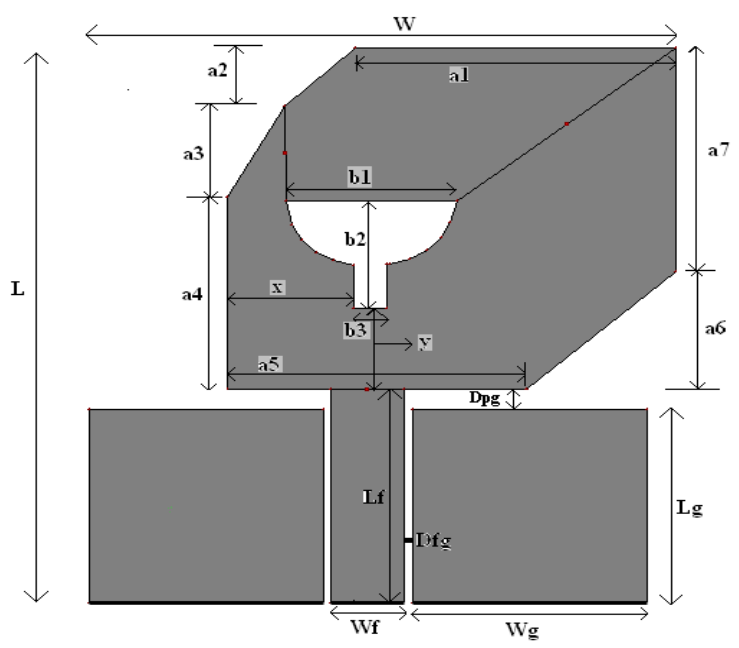

Fig 1: Geometry of proposed Antenna 
Table 1: Parameters of the proposed antenna

\begin{tabular}{|l|l|l|l|l|l|}
\hline $\begin{array}{l}\text { Para- } \\
\text { meter }\end{array}$ & $\begin{array}{l}\text { Size (in } \\
\text { mm) }\end{array}$ & $\begin{array}{l}\text { Para- } \\
\text { meter }\end{array}$ & $\begin{array}{l}\text { Size } \\
\text { (in } \\
\text { mm })\end{array}$ & $\begin{array}{l}\text { Para- } \\
\text { meter }\end{array}$ & $\begin{array}{l}\text { Size } \\
\text { in } \\
\text { mm })\end{array}$ \\
\hline L & 39 & Dfg & 0.5 & a7 & 15.7 \\
\hline W & 36.275 & a1 & 19.75 & b1 & 10.55 \\
\hline Lg & 13.6 & a2 & 4 & b2 & 7.5 \\
\hline Wg & 14.5 & a3 & 6.5 & $\mathrm{~b} 3$ & 1.975 \\
\hline Lf & 15 & a4 & 13.5 & $\mathrm{x}$ & 7.8 \\
\hline Wf & 4.5 & a5 & 18.375 & y & 5.75 \\
\hline Dpg & 1.4 & a6 & 8.3 & & \\
\hline
\end{tabular}

\section{SIMULATED RESULTS AND DISCUSSIONS}

The simulated return losses and other parameter results are obtained. The return losses of the proposed antenna are shown in Figure 2. The result shows that the antenna exhibits an ultrawideband and impedance bandwidth is $7.39 \mathrm{GHz}$ ranging from 2.66 GHz to $10.05 \mathrm{GHz}$. This implies that it also covers WLAN band from 5.15-5.35/ 5.75-5.85 GHz, Wi-MAX band from 3.43.7/5.15-5.35/5.47-5.725/5.725-5.825 GHz.

Figure 3 shows the parametric study of the proposed antenna. It shows the graph of return losses when distance between patch and ground, is varied and effect of slot addition on antenna performance. It is clearly shown in figure. 3 , that on addition of slots bandwidth is increased and by doing variations in Dpg, the magnitude of return losses is increased but in that case ultrawideband is not achieved. In this way optimum results are obtained by doing these variations.

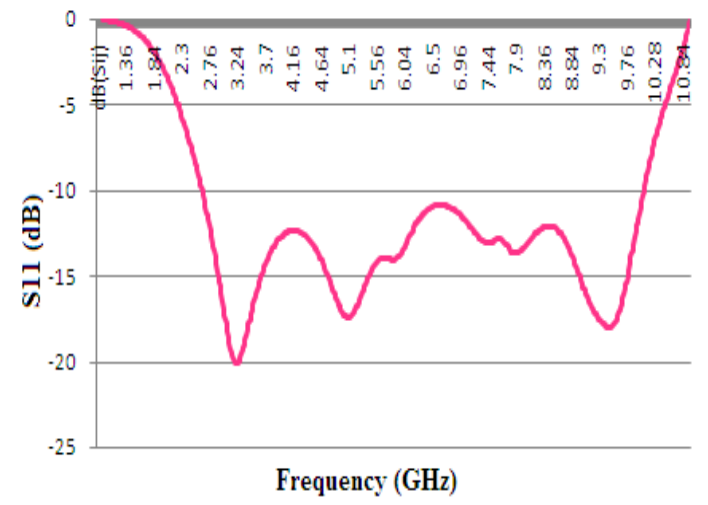

Fig 2: Return loss of proposed antenna

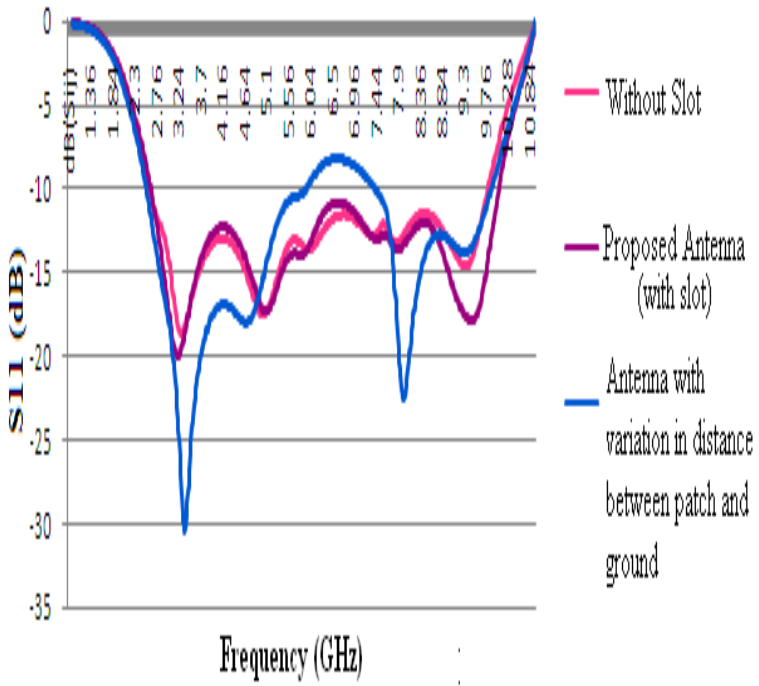

Fig 3: Parametric Study of Proposed Antenna

The proposed antenna has two main resonant frequencies: 3.25 , $5.11 \mathrm{GHz}$. In figure 4 and 5 simulated 2D radiation patterns for elevation and azimuthal plane near at resonant frequencies 3.25 $\mathrm{GHz}$ and $5.11 \mathrm{GHz}$ respectively are shown. Radiation pattern presents the graphical representation of radiation properties of antenna as a function of space co-ordinates. Figure 6 shows three dimensional radiation pattern of proposed antenna at 3.25 $\mathrm{GHz}$ and $5.11 \mathrm{GHz}$.

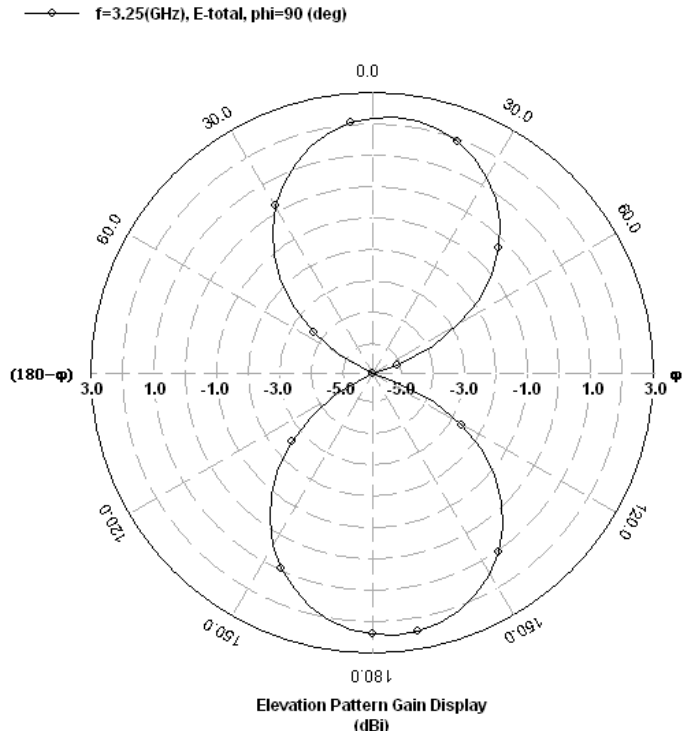

Fig 4(a): Elevation pattern at $3.25 \mathrm{GHz}$ 


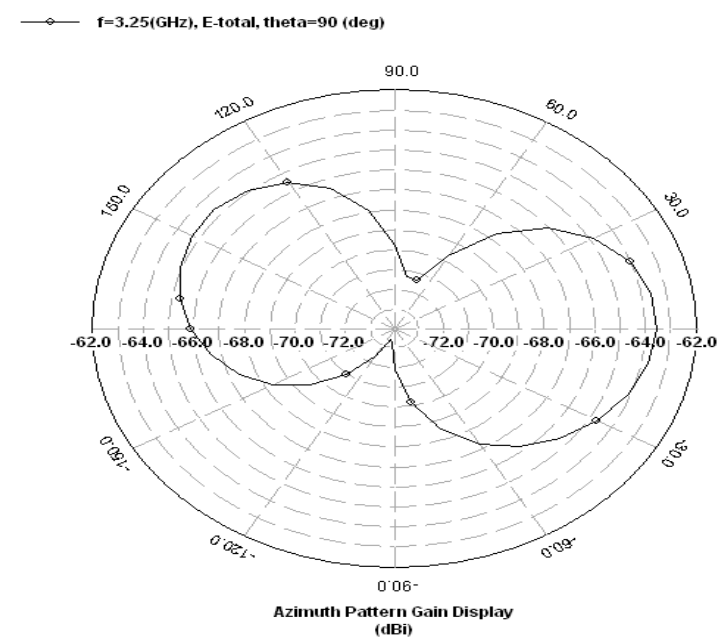

Fig 4(b): Azimuthal pattern at $3.25 \mathrm{GHz}$

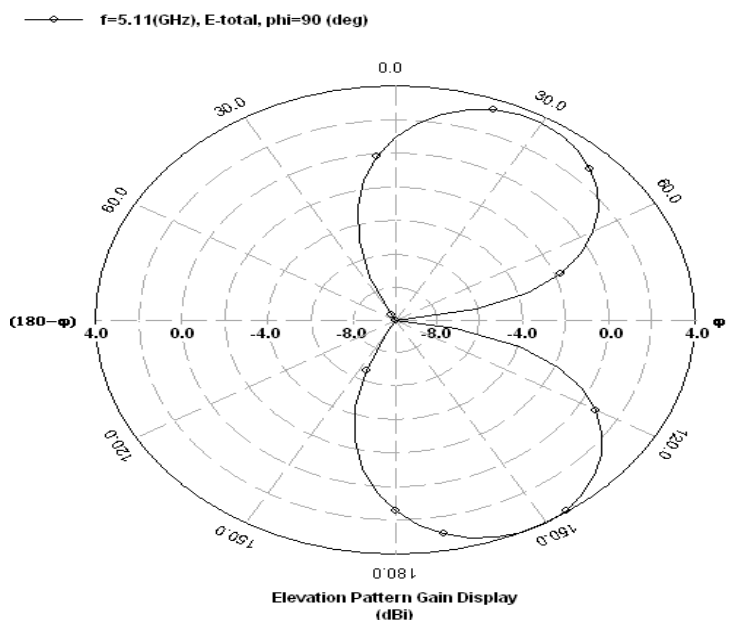

Fig 5(a): Elevation pattern at $5.11 \mathrm{GHz}$

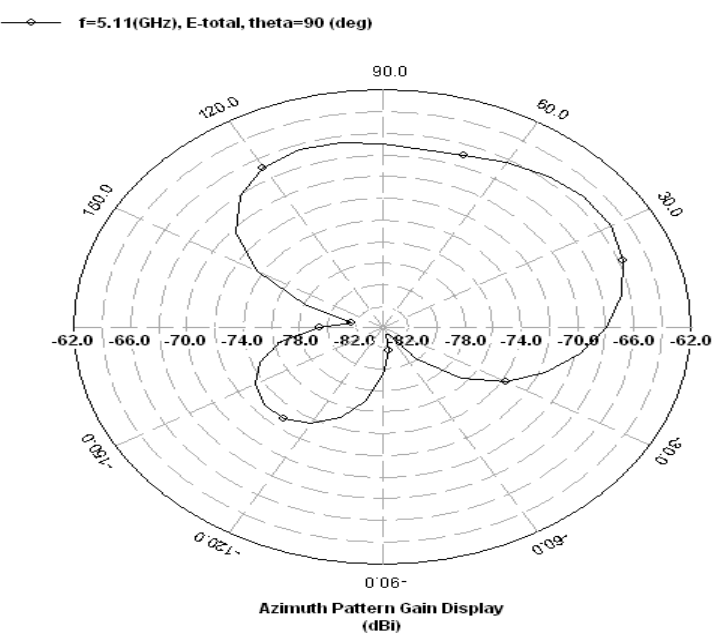

The formation of the frequency resonances can be explained by observing the surface currents on the conductors of the antenna at $3.25 \mathrm{GHz}, 5.11 \mathrm{GHz}$ as shown in Figure 7. Current distribution is changed by changing the length and dimensions of patch. The maximum E-current at $3.25 \mathrm{GHz}$ is $11.172 \mathrm{~A} / \mathrm{m}$ and at $5.11 \mathrm{GHz}$ is $12.54 \mathrm{~A} / \mathrm{m}$.
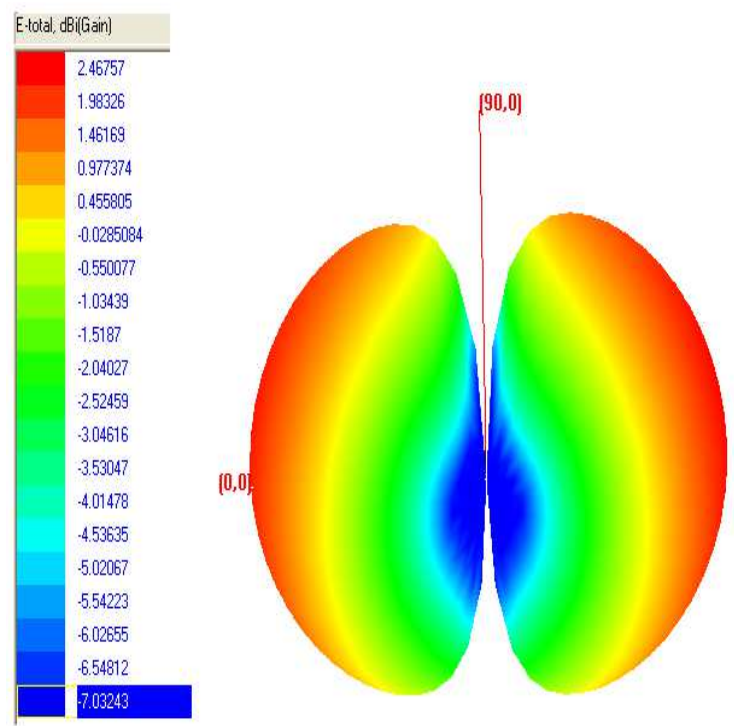

Fig 6 (a): 3-Dimensional Pattern of Proposed Antenna at 3.25 $\mathrm{GHz}$
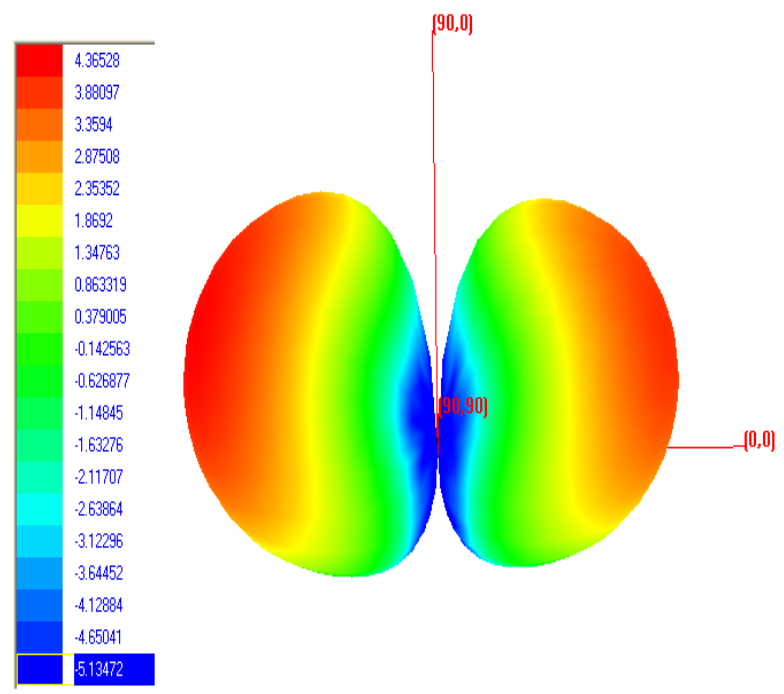

Fig 6 (b): 3-Dimensional Pattern of Proposed Antenna at 5.11 $\mathrm{GHz}$

Fig 5(b): Azimuthal pattern at $5.11 \mathrm{GHz}$ 


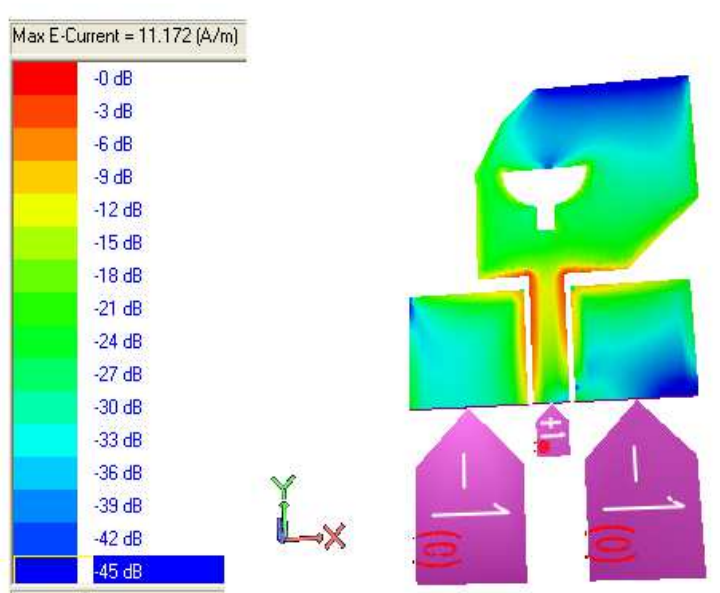

Fig 7(a): Current distribution of proposed Antenna at $3.25 \mathrm{GHz}$
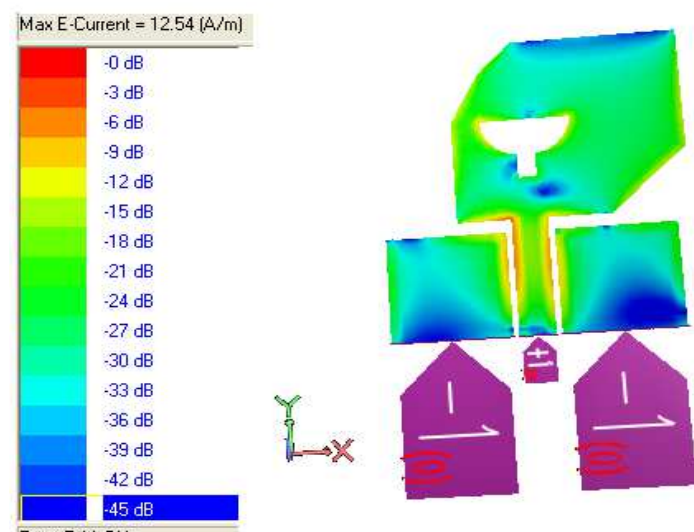

Freq: $5.11 \mathrm{GHz}$

Fig 7(b): Current distribution of proposed Antenna at $5.11 \mathrm{GHz}$

The graph for VSWR (Voltage Standing Wave Ratio) is shown in Figure 8.

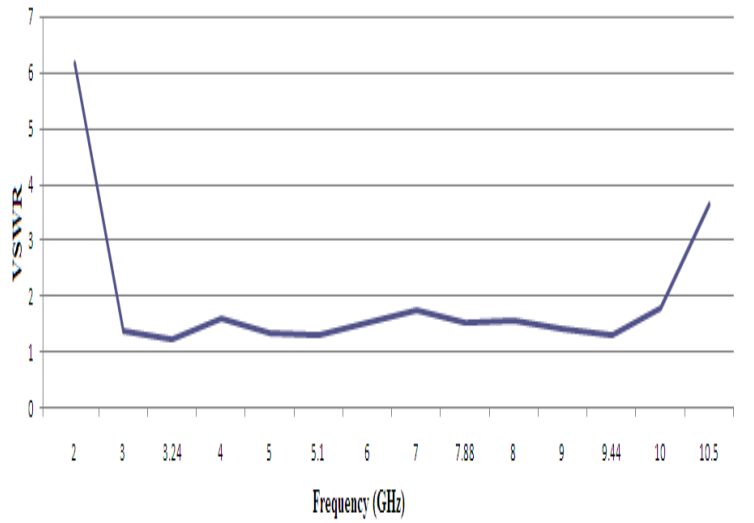

Fig 8: VSWR versus Frequency

\section{CONCLUSIONS}

In this investigation, an ultra-wideband microstrip antenna fed by Coplanar Waveguide (CPW) feed is proposed. The proposed antenna has compact size of $39 \times 36.275 \times 1.6 \mathrm{~mm} 3$ and achieves ultra-wide frequency band having wide impedance bandwidth of $7.39 \mathrm{GHz}$ covering wireless local area network (WLAN) and worldwide interoperability for microwave access (WiMAX) bands also. The various antenna parameters like S-parameters, current distribution and radiation pattern are studied. It can be concluded from the results that the designed antenna has satisfactory performance and hence can be used for broadband wireless communication systems.

\section{REFERENCES}

[1] Ching-Fang Tseng and Cheng-Liang Huang, "A Wideband Cross Monopole Antenna" IEEE Transactions on Antennas And Propagation, Vol. 57, No. 8, August 2009.

[2] Fangfang Fan, Zehong Yan, Tianling Zhang, and Yue Song, "Ultra Wideband Planar Monopole Antenna With Dual Stopbands" Microwave And Optical Technology Letters, Vol. 52, No. 1, January 2010.

[3] Rui-Jin Lin, Y. E. Ming, and Xiao-Zheng Lu, "A Novel Key-Shaped CPW-Fed Monopole UWB Antenna" Microwave And Optical Technology Letters, Vol. 52, No. 4, April 2010.

[4] S-M. Zhang, F.-S. Zhang, W.-Z. Li, T. Quan and H.-Y. Wu, "A Compact UWB Monopole Antenna With WiMAX and WLAN Band Rejections" Progress In Electromagnetics Research Letters, Vol. 31, pp. 159168, 2012.

[5] Pawan Kumar, Malay Ranjan Tripathy, H.P. Sinha, "Wide band Slotted Microstrip Antenna for Wireless communications" International Journal of Electronics and Computer Science Engineering, ISSN 22771956/V2N1, pp. 301-305, 2013.

[6] X.-C. Yin, C.-L. Ruan, C.-Y. Ding, and J.-H. Chu, "A Planar U Type Monopole Antenna for UWB Applications" Progress In Electromagnetics Research Letters, Vol. 2, pp. 1-10, 2008

[7] Bharat Rochani, Sanjay Gurjar, "H And U-Slotted Rectangular Microstrip Patch Antenna" International Journal of Electronics and Computer Science Engineering, ISSN 2277-1956/V1N4-2557-2561, 2012

[8] Astt.Prof. Abhishek Choubey, Rachna Pal, "Hexagonal Shaped Ultra Wide Band Patch Antenna with Pyramid Shaped fractal in Ground Plane" International Journal of Electronics and Computer Science Engineering, ISSN 2277-1956/V1N4, pp. 1975-1981 


\section{BIOGRAPHIES}

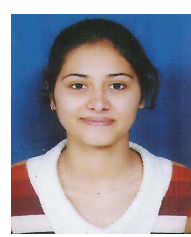

Supriya Arora was born in Haryana, India in 1990. She received B.Tech degree from Deptt. of Electronics and Communication Engineering at HCTM, Kaithal (Haryana) in 2011. She is currently working toward a M.Tech degree at HCTM, Kaithal (Haryana). She has published three papers in international conference/journals.

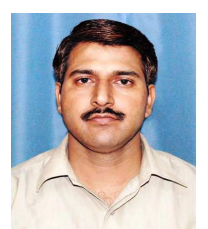

Davinder Parkash was born in Haryana, India in 1976. He received B.Tech. and M.Tech. degree from the Deptt. of Electronics and Communication Engineering at Kurukshetra University, Kurukshetra and NIT, Kurukshetra in 1999 and 2007 respectively. He is currently working toward a $\mathrm{PhD}$. degree at Thapar University, Patiala. $\mathrm{He}$ is currently working as Assoc. Prof. and M.Tech. Coordinator at Department of ECE at Haryana College of Technology and Management, Haryana Presently, he is also working as Branch-Counselor of IEEE student chapter. He received the 'Young Scientist Award' from the Governor of Punjab (India). He has published more than 45 papers in national and international journal/conferences. He is Member of IEEE (Since 2010) and member of Microwave Theory and Technique society membership no.-90859628 and member of Antenna Propagation Society. His main research interest includes the analysis and design of microstrip antenna, DGS technique, RFID antenna, and Wireless Communication. 